\title{
Evoking Cognitive Conflict and Intellectual Awareness of Students: A study in the topic of combinatorics
}

\author{
Djadir \\ Faculty of Mathematics and Science \\ Universitas Negeri Makassar \\ Makassar, South Sulawesi, Indonesia
}

\author{
Muhammad Dinar \\ Faculty of Mathematics and Science \\ Universitas Negeri Makassar \\ Makassar, South Sulawesi, Indonesia
}

\author{
Fajar Arwadi \\ Faculty of Mathematics and Science \\ Universitas Negeri Makassar \\ Makassar, South Sulawesi, Indonesia
}

\begin{abstract}
The present study was a part of a broader research aimed at designing instructional learning which can evoke students' conflict cognitive and intellectual awareness. The specific purposes of this study were reviewing factors which can evoke conflict cognitive and intellectual awareness of students and designing a basis model to create an instructional learning. Literature studies were applied in two main parts. Firstly, the study reviewed the stages of conflict cognitive process and intellectual awareness including their destructive factors. The second, the study reviewed several strategies in solving these problems. The findings suggest that there are some factors which can hamper the occurrence of cognitive conflict and intellectual awareness of which one of them is mathematics anxiety. These factors can be overcome by inducing and applying pivotal counterexample, problem solving strategy, and realistic mathematics education to the basic model of learning instructional design.
\end{abstract}

Keywords: Evoking, Cognitive Conflict; Intellectual Awareness

\section{INTRODUCTION}

One of the crucial problems in learning mathematics is a misconception. It can be caused by the poor quality of teacher's teaching, the inexactness way of students' thinking, and the lack memory of students about a lesson in the past. It doesn't only have an impact on the outcome of learning in the present situation but also negatively affects learning process in the future. In addition, a learning difficulty obstructing mathematics learning process which is likely caused by misconception is the mistake of students in solving problems.

One of the states which can overcome such learning difficulties e.g. misconception and mistake of solving problems and give progressive development to the knowledge of students is cognitive conflict [1]. Cognitive conflict is a psychological theory related to cognitive change. Lee and Kwon defined that a condition in which one sees the discrepancy between one's own cognitive structure and external information or some parts of his cognitive structure (conception, knowledge, etc) [2]. Moreover, Lee et al. argued that students will not alter their conceptions before they experience cognitive conflict which contradicts a new concept with their conceptions [3].
The learning which aims to elicit cognitive conflict is assisting students to reflect their understandings then contradicting it in such a way that they realize some or even all of the conceptions are not true which consequently make them aware of the importance of changing the concept. The term of the awareness is called "intellectual awareness".

A kind of research aimed to create a theory and instructional learning design is design research [4]. Although there are several types of research concerning cognitive conflict, researches of instructional learning designs about specific mathematics topics to evoke cognitive conflict and to promote intellectual awareness in order to correct the mistake of students' cognitive structure are still not extensive. There is no theoretical framework model which can be applied to design a learning instructional to reach those two aims.

Consequently, it attracts the authors' interest to design the model which can be made as a basis to create a desired learning instructional design. The topic under discussion in this study is combinatorics. The topic was chosen based on the literature review conducted by the authors related to the kinds of students' errors in solving combinatorics problems [5]. Specifically, the problem of this study is that "how to create a model which can be used as a basis to design an instructional learning which can both evoke cognitive conflict of students and raise the intellectual awareness to ameliorate the condition?"

\section{RESEARCH METHOD}

As previously described in the introduction part, the present research has two hierarchy specific objectives i.e. examining situations which can elicit cognitive conflict and intellectual awareness of students as well as designing model which can be used as a basis to create instructional learning design to achieve the goals. Therefore, in this section, the method for this study is discussed.

In specific, this study used literature review. To achieve the first objective, the authors studied the literature related to the development of cognitive conflict. Since it was assumed that the cognitive conflict could be destructive, then this study comprehends of two sections. Firstly, it analyzes the stages of 
which students experience cognitive conflict as well as the potencies which cause the cognitive conflict and intellectual awareness not occur. Secondly, it examines pedagogical constructive theories which can be set as the reference to solve the unexpected destructive things as well as evoke the cognitive conflict and raise the intellectual awareness of students.

To accomplish the second purpose, this study used the theory of design research method. According to Gravemeijer \& van Eerde, design research is a method aimed to develop a local instructional theory led by the cooperation between researchers and teachers to improve the quality of learning [4]. One of the products of design research is the sequence of activities of students consisting of strategy conjectures and thoughts which are under control and facilitated by teachers. Therefore, the authors specifically design the theoretical framework of teachers' activity to evoke the cognitive conflict and intellectual awareness of students as the basis for one who will develop an instructional learning.

\section{DISCUSSION}

\section{A Combinatorics}

Based on the curriculum in universities, the topics of combinatorics are generally included in discrete mathematics subject. The subject plays a role as a science which is related, one of them, computer science. Therefore, besides combinatorics, the subject has varieties of topics such as logic, relation and function, recursive relation, generating function, set theory, number theory, etc. Hadar \& Hadass argued that the mistake and the misconception of students of combinatorics mostly stem from solving a problem [6]. Consequently, it is the reference for this study to pose a problem in the beginning part of the instructional learning design.

\section{$B$ Stages of Cognitive Conflict}

There are several treatments which are essential to apply to elicit the cognitive conflict of students [7]. In general, information contradictive to the conception of students is provided through text book, experiment, simulation, and even a discussion with a group of students against to the students. However, the contradictive situation is not necessarily in evoking cognitive conflict of students [8]. In addition, cognitive conflict strategy does not absolutely cause students' intellectual awareness implying the old conception is not changed [9].

As the referral to create the framework of cognitive conflict process, Lee et al. developed a model to describe cognitive conflict stages taking place when students face an uncommon situation which is not relevant to their conceptions [3]. These stages consist of: preliminary, conflict, and resolution. The preliminary part occurs when students who have their own conceptions receive an irrelevant situation as real. When students don't understand new conception or except it as an exception, then the cognitive conflict doesn't occur. Simply, the model describes that cognitive conflict occurs when students understand new situation, show interest or anxiety about solving the conflict, and make a decision about the present situation. Moreover, he suggested that the components such as recognition, interest, and anxiety related to uncertainty are considered as the indications of conflict cognitive. After experiencing this stage, students will decide whether they want to solve the conflict or ignore it. In the resolution stage, the students try to solve the conflict.

It can be assumed that the intellectual awareness of students potentially fails to occur in the stages of cognitive conflict process. In the preliminary stage, when students do not understand a new situation or feel unpleasant to a conflict state, then the cognitive conflict does not occur and neither the intellectual awareness. In the conflict stage, when students strongly feel anxiety, frustration, and threat, then the cognitive conflict is destructive for students and consequently detains the intellectual awareness. In the resolution stage, it is likely for the intellectual awareness of students fail to occur when students make a wrong decision i.e. they still keep believing that their conceptions are true. Therefore, based on the discussions, the destructive things which can hamper the occurrence of cognitive conflict and intellectual awareness are that, students don't understand a new concept implying cognitive conflict fail to occur, a learning is not able to make students aware which causes cognitive conflict not taking place, students do not feel comfortable or have anxiety, frustration, threat, then they ignore conflict situation, students defend their wrong conceptions.

\section{$C$ The problem solvings on the destructive situations}

\section{1) Pivotal counterexamples and problem solving} strategies

Zazkis and Chernoff argued that pivotal counterexamples can be addressed in an instructional learning design to anticipate a state of which students confront with contradictive conceptions [10]. A counterexample is said to be pivotal for students when the example leads a "turning point" to their conceptions, i.e., the example causes a dissonance to the wrong or lack of understanding of students. In other words, the example elicits cognitive conflict of students. Unlike counterexamples in mathematics which can be universally determined, pivotal counterexamples can be recognized only after the example is used in a learning activity. Such example, according to Lee et al. is an example causing a situation which is not appropriate to the knowledge of students [3].

atson and Mason in Stylianides and Stylianides defined that example space is a collection of examples which have a specific function [11]. They further argued that a counter example which can be pivotal for students generally satisfy the following criteria: (1) in the outside of personal example space of students but immediately and easily understood, and (2) inside of personal potential example space of students, i.e. the example has been in students' conception. One of the reasons why a counter example fails to be pivotal for students is that the example is outside of personal potential example space of students. The second condition to increase the possibility of an 
example becomes a pivotal counterexample is to help students to increase their awareness. For instance, it can be an instruction "give an example of number needed to show the formula valid!".

There is a connection between the problem solving strategy by Eizenberg and Zaslavsky and the pivotal counterexamples [12]. One of the strategies is problem simplification to ease the process of solving a problem. The application of the strategy potentially evokes students to make example inside their example space. However, they argued that the application is not simple to do without the guide of teachers. Hence, the guide of teachers should be set in an instructional activity of a learning design.

Moreover, pivotal counterexamples potentially increase the understanding of students. It is caused that making examples by students can improve their understandings [13]. The making of example plays an important role to the mathematics concept exploration. Teachers frequently provide examples to help students understand many topics. However, the giving of examples is likely to make students passive and it is problematic in learning [14]. To understand a topic comprehensively, Watson and Mason suggested that students are given an opportunity to make examples by themselves [11]. One of the strengths of this method is that students are able to extensively understand topics which are learned and obtain new knowledge of the concept of the topics.

\section{2) Realistic Mathematics Education}

Besides the conditions to set pivotal counterexamples, the authors also relate the concept of realistic mathematics education (RME) and pivotal counterexamples. RME is a learning approach based on the principle of Hans Freudenthal $(1905$ - 1990) that mathematics is human activity. One of the characteristics of RME is the construction process of knowledge comes from the real world or something which are imaginable by students [15].

Consequently, the authors infer that RME approach can be used as a basis to make a counter example become pivotal for students since, from the application of RME, learning instruction provides familiar examples for students and they are given a chance to give contribution i.e. examples which are appropriate to the second condition of pivotal counterexamples. Furthermore, another characteristic of RME which uses context familiar to students as ground starting for learning mathematics can minimize anxiety attitude. It is caused by the lesson material or the knowledge of students is an important thing to take into account before giving them a lesson [16].

Therefore, based on those descriptions, a framework model of instructional learning design which can elicit the cognitive conflict and raise the intellectual awareness of students is as follows Figure 1.

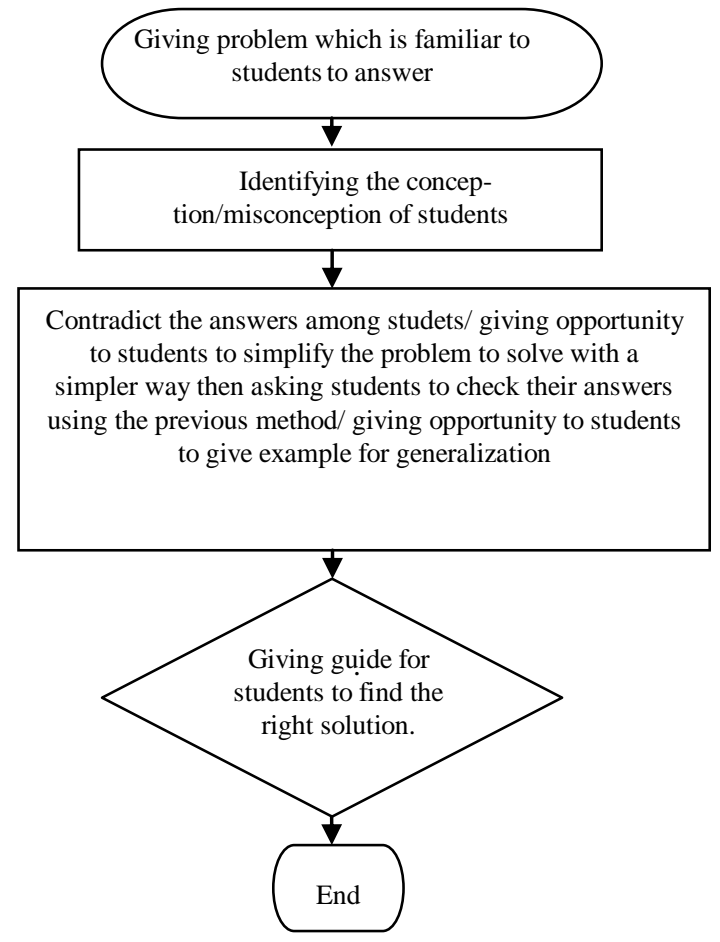

Fig. 1. Model of instructional learning design

\section{CONCLUSION}

Based on the present study, it can be concluded that to evoke the cognitive conflict and intellectual awareness of students in a combinatoric learning can be commenced from a problem posing. From the process of solving the problem, if there is, the misconception of students can be identified. There are some destructive situations which can be obstacles for cognitive conflict and intellectual awareness. They can be solved by applying the use of pivotal counter examples, problem simplification strategy, and also RME approach.

\section{REFERENCES}

[1] N. Hadas, R. Hershkowitz, and B. B. Schwarz, 'The role of contradiction and uncertainty in promoting the need to prove in dynamic geometry environments', Educ. Stud. Math., vol. 44, no. 1, pp. 127-150, 2000.

[2] G. Lee and J. Kwon, 'What Do We Know about Students' Cognitive Conflict in Science Classroom: A Theoretical Model of Cognitive Conflict Process.', 2001

[3] G. Lee, J. Kwon, S. Park, J. Kim, H. Kwon, and H. Park, 'Development of an instrument for measuring cognitive conflict in secondary- level science classes', J. Res. Sci. Teach., vol. 40, no. 6, pp. 585-603, 2003.

[4] K. Gravemeijer and D. van Eerde, 'Design research as a means for building a knowledge base for teachers and teaching in mathematics education', Elem. Sch. J., vol. 109, no. 5, pp. 510-524, 2009.

[5] S. Kavousian, 'Enquiries Into Undergraduate Students â€ $€^{\mathrm{TM}}$ Understanding Of Combinatorial', 2008.

[6] N. Hadar and R. Hadass, 'The road to solving a combinatorial problem is strewn with pitfalls', Educ. Stud. Math., vol. 12, no. 4, pp. 435-443, 1981.

[7] P. R. Pintrich, 'Motivational beliefs as resources for and constraints on 
conceptual change', New Perspect. Concept. Chang., vol. 33, p. 50, 1999.

[8] C.-C. Tsai, 'Enhancing science instruction: the use of'conflict maps", Int. J. Sci. Educ., vol. 22, no. 3, pp. 285-302, 2000.

[9] G. M. Sinatra and P. R. Pintrich, Intentional conceptual change. Routledge, 2003.

[10] R. Zazkis and E. J. Chernoff, 'What makes a counterexample exemplary?', Educ. Stud. Math., vol. 68, no. 3, pp. 195-208, 2008.

[11] A. J. Stylianides and G. J. Stylianides, 'Cognitive Conflict'as a mechanism for supporting developmental progressions in students' knowledge about proof', in Online Proceedings of the 11th International Congress on Mathematical Education (ICME), under Topic Study Group, 2008, vol. 18.

[12] M. M. Eizenberg and O. Zaslavsky, 'Cooperative problem solving in combinatorics: the inter-relations between control processes and successful solutions', J. Math. Behav., vol. 22, no. 4, pp. 389-403, 2003.

[13] S. Kavousian, 'Enquiries into undergraduate students' understanding of combinatorial structures'. Faculty of Education-Simon Fraser University, 2008 .

[14] O. Hazzan and R. Zazkis, "A perspective on" give an example" tasks as opportunities to construct links among mathematical concepts', Focus Learn. Probl. Math., vol. 21, no. 4, pp. 1-14, 1999.

[15] K. Gravemeijer, 'Local instruction theories as means of support for teachers in reform mathematics education', Math. Think. Learn., vol. 6, no. 2, pp. 105-128, 2004.

[16] E. Geist, 'The anti-anxiety curriculum: Combating math anxiety in the classroom', J. Instr. Psychol., vol. 37, no. 1, p. 24, 2010. 